\title{
Social structure in synanthropic populations of a murid rodent Mastomys natalensis in Sénégal
}

\author{
Laurent GRANJON and Jean-Marc DUPLANTIER
}

\begin{abstract}
Granjon L. and Duplantier J.-M. 1993. Social structure in synanthropic populations of a murid rodent Mastomys natalensis in Sénégal. Acta theriol. 38: 39 - 47.

Synanthropic populations of Mastomys natalensis (A. Smith, 1834) were studied in southeastern Sénégal in order to evaluate some elements of their social structure. Analysis of trapping data consisting in single and multiple captures indicates that adult males were less likely to be involved in multiple captures than any other category of individuals. Sex-ratio in adults was significantly female-biased, and multiple captures involving 4 individuals or more (up to 13) were characterized by the small number of adult males involved (usually one per capture). Dyadic encounters between males revealed a higher rate of aggressive behaviours in $M$. natalensis than in its sibling species $M$. huberti. These observations suggest that these synanthropic populations are subdivided in polygynous units in which: (1) a part of males are evicted from the social group before their maturity and (2) adult males of different social units display aggressive behaviour towards each other.
\end{abstract}

Laboratoire de Zoologie, Mammiferes et Oiseaux, Muséum National d'Histoire Naturelle, 55 rue Buffon, 75005 Paris, France (LG), Programme "Eau et Sante", Orstom, BP 1386, Dakar, Sénégal (JMD)

Key words: Mastomys natalensis, synanthropy, interindividual associations, intermale interactions, sex-ratio

\section{Introduction}

Social structuring of mammalian populations may be an important factor accounting for the rapid rate of evolutionary change observed in this class of vertebrates (Wilson et al. 1975, Bush et al. 1977, Lande 1979). By reducing effective population sizes, social subdivisions may actually promote genetic differentiation bitween the isolated units, the prerequisite for any significant evolutionary divergence to occur (Chepko-Sade and Shields 1987). In this respect, some particular aspects of social organization have been considered in relation with their ecological correlates and genetical consequences: spatial patterns and dispersal (Mihok 1979, Shields 1987, Zwicker 1989), group structure and mating system (Crook et al. 1976, Emlen and Oring 1977, Dobson 1982, Shields 1987, Wade and Breden 1987) and sex-ratio (Leigh 1970, Wilson and Colwell 1981, Cockburn et al. 1985, Futuyma 1986).

One particular environment is represented by man-made habitats where, among others, ressource distribution and habitat structure impose new selective 
pressures on synanthropic populations. The purpose of this study is to evaluate some components of the social organization (group structure, sex-ratio, interindividual interactions) of synanthropic populations of an African murid rodent Mastomys natalensis (A. Smith, 1834), from field and laboratory data. This species of wide distribution in Africa (Rosevear 1969) is often associated with humans (Kingdon 1974, De Graaf 1981), yet its social structure in natural conditions is poorly known. $M$. natalensis was recently discovered in Sénégal where it coexists with $M$. erythroleucus and $M$. huberti (Duplantier and Granjon 1988). Moreover, the genus Mastomys is characterized by a great range of inter- and intra-specific karyological variability (Hubert et al. 1983, Duplantier et al. 1990a), associated with little morphological and genetical differentiation (Rosevear 1969, Duplantier 1988, Robbins and Van der Straeten 1989, Duplantier et al. 1990b).

\section{Materials and methods}

\section{Study area}

The range of $M$. natalensis in Sénégal is restricted to the south-eastern part of the country where the species is exclusively synanthropic (Duplantier and Granjon 1988). Trapping was conducted mainly in eight villages of the Department of Kedougou (region of Tambacounda: Kedougou, Fadiga, Ibel, Tiangel-Malal, Segou, Bransan, Dakateli and Bombou-Mandingue) during five periods: March 1985, January, March and September 1986, and February 1989. Traps were set in dwellings either built of concrete or traditionnally-built (ramned-clay or stone). Dwellings are usually grouped in plots, each of them comprising a few habitations and being separated from the next one by a palisade.

\section{Trapping procedure}

Two types of traps were employed: "single-capture" live traps (Firobind $25 \times 8 \times 8$ and Manufrance $26 \times 9 \times 10 \mathrm{~cm}$ ) and multiple-capture live traps (Manufrance $38 \times 13 \times 13 \mathrm{~cm}$, equiped with a gravity-closing door). They were baited with peanut butter, set in dwellings in the afternoon, and checked in the morning, as M. natalensis in Sénégal is mainly nocturnal (Duplantier and Granjon 1990). The traps were left one or a few nights in the same place, according to the results. The captured individuals were weighed and their sex and reproductive condition recorded. Adults and juveniles were distinguished according to weight and external signs of sexual maturity (testes position in males, opening of the vagina in females). All the trapped animals were brought to the laboratory for behavioural tests and for the establishment of a breeding colony.

Multiple captures (i.e. captures of two or more individuals in the same trap: up to 13 in multiple-capture traps, up to 5 in "single-capture" traps) were obtained with both types of traps, and were given the same meaning in terms of social relationships: individuals trapped together in a "single-capture" trap necessarily entered the trap almost simultaneously (i.e. they were moving around together); individuals trapped together in a multiple-capture trap either were together when captured (simultaneous capture), or were attracted by each others (successive captures). In all cases, and in the absence of external signs of interindividual aggressiveness in the traps, we considered multiple captures as being the result of probable social attraction. Conversely, single captures in both types of traps were interpreted as the absence of such a behaviour in the individuals (or categories) concerned. More details on methodology are given in Granjon and Duplantier (1991).

From trapping data, the following two hypothesis were tested with Slade's (1976) method: (1) inc'ependance of category and probability of single or multiple capture and (2) randomness of associations of particular pairs of categories. For this test, data from "single-" and multiple-capture 
traps were pooled. This was justified by the results of preliminary analysis showing that the data gathered with the two types of traps were only slighly different (Granjon and Duplantier 1991). A contingency table and Chi-square test were used for both tests. As underlined by Slade (1976), these tests are unaffected by any differential trappability between categories, because the actual numbers of captures are used for generating the expected values.

\section{Laboratory tests}

Dyadic encounters were performed between adult males within one week after their capture. Two males of similar weight and from the same origin (village) were opposed in a test arena composed of two wooden cages $(60 \times 40 \times 40 \mathrm{~cm})$ with a plexiglas front and a sandy bottom. The animals were first isolated for a few minutes until they get used with their environment. Then, the communication door between the cages was removed, and the 10-minute test started when one individual entered the cage of the other one. Each animal was tested once only, and the experimental arena was cleaned (sand changed and walls washed) between the tests. A number of behavioural patterns were recorded, following Grant and MacIntosh (1963) and Eisenberg (1967). They were classified into 4 categories, according to their apparent motivational similarity:

- approach towards the other individual,

- neutral contacts including nasal investigations (contacts and/or sniffing), following of one individual by the other, huddling and allo-grooming,

- aggressive acts, including attacking, chasing, fighting and offensive posture (= threatening),

- defensive acts, including retreating, fleeing, defensive and submissive posture.

Twenty-four adult males of $M$. natalensis were tested in 12 dyadic encounters. The results of 16 dyadic encounters of 32 males of the sibling species $M$. huberti, tested in the same experimental conditions, were considered for comparison. These animals originated from a cultural irrigated zone, (north of Dakar), typical of the outdoors humid biotopes where the species live (Duplantier and Granjon 1988). Differences in the percentages of occurrence of the behavioural categories between the two samples were tested by non-parametric Mann-Whitney tests (Siegel 1956).

\section{Results}

\section{Trapping data}

Altogether, 433 individuals were trapped, $43 \%$ of which were juveniles (Table 1). Juveniles were found during each sampling period, and reached their highest proportion $(45-50 \%)$ in January-February. In this age class, sex-ratio is unbiased at any period, whereas it is regularly female-biased in adults (Table 1). The global sex-ratio is at equilibrium in juveniles but significantly female-biased in adults, with approximately two females for one male trapped.

Among these 433 individuals, 273 were trapped in multiple captures, and 160 in single ones. The tendency of individuals of the different categories (adult males or females, juvenile males or females) to be involved in single or multiple captures was tested by a $2 \times 4$ contingency table (Table 2 ). The proportion of single captures was higher in adult males than in adult females and juveniles. On the other hand, adult males were less often involved in multiple captures than any other animal group.

The test for randomness of the distribution of double captures between the different classes of individuals indicated that expected and observed associations did not differ significantly (Table 3). 
Table 1. Numbers of adults and juvenile males and females of $M$. natalensis and percentages of juveniles during each trapping session in south-eastern Sénégal. $n$ - number of sampled villages, ${ }^{* * *}-p<0.001, \chi^{2}$ test of sex ratio.

\begin{tabular}{lcccc}
\hline & $n$ & ad males/females & juv males/females & \% juveniles \\
\hline March 1985 & 4 & $19 / 41^{* * *}$ & $19 / 16$ & 37 \\
January 1986 & 5 & $38 / 73^{* * *}$ & $59 / 51$ & 50 \\
March 1986 & 1 & $6 / 6$ & $1 / 3$ & 25 \\
September 1986 & 4 & $15 / 25$ & $8 / 11$ & 32 \\
February 1989 & 2 & $7 / 16$ & $6 / 13$ & 45 \\
Total & 16 & $85 / 161^{* * *}$ & $93 / 94$ & 43 \\
\hline
\end{tabular}

Table 2. Observed and expected (in brackets) numbers of single and multiple captures of the different categories of individuals of $M$. natalensis $\left(\chi^{2}=7.87, p<0.05\right)$.

\begin{tabular}{lcccc}
\hline & ad male & ad female & juv male & juv female \\
\hline Single & $41(31)$ & $61(59)$ & $27(34)$ & $31(35)$ \\
Multiple & $44(54)$ & $100(102)$ & $66(59)$ & $65(59)$ \\
\hline
\end{tabular}

Table 3. Distribution of double captures in $M$. natalensis: observed numbers in the superior half of the table, expected numbers in the inferior half $\left(\chi^{2}\right.$ $=8.7,0.10>p>0.05$, after combining juvenile male and female numbers).

\begin{tabular}{|c|c|c|c|c|c|}
\hline & & \multicolumn{2}{|c|}{ adults } & \multicolumn{2}{|c|}{ juveniles } \\
\hline & & male & female & male & female \\
\hline \multirow[t]{4}{*}{ adults } & male & 6 & 16 & 5 & 0 \\
\hline & & 3.5 & & & \\
\hline & female & 13.4 & 12 & 10 & 13 \\
\hline & & & 12.7 & & \\
\hline \multirow[t]{4}{*}{ juveniles } & male & 7.2 & 13.8 & 6 & 7 \\
\hline & & & & 3.7 & \\
\hline & female & 5.5 & 10.5 & 5.8 & 3 \\
\hline & & & & & 2.2 \\
\hline
\end{tabular}

Observed distributions of individuals in triple captures $(n=16)$ as a function of sex or age were close to expected, but numbers were too small to be tested statistically (Table 4). Multiple captures of four individuals or more (up to 13) 
Table 4. Observed and expected numbers of triple captures of $M$. natalensis as a function of sex ( $\mathrm{m}-$ male, $\mathrm{f}-\mathrm{female})$ and age (ad - adult, juv juvenile).

\begin{tabular}{lcccc}
\hline & ad ad ad & ad ad juv & ad juv juv & juv juv juv \\
\hline Observed & 4 & 3 & 7 & 2 \\
Expected & 2.3 & 6.2 & 5.7 & 1.8 \\
\hline & $\mathrm{m} \mathrm{m} \mathrm{m}$ & $\mathrm{m} \mathrm{m} \mathrm{f}$ & $\mathrm{m} \mathrm{ff}$ & $\mathrm{fff}$ \\
\hline Observed & 2 & 6 & 3 & 4 \\
Expected & 1.5 & 5.2 & 6 & 2.3 \\
\hline
\end{tabular}

Table 5. Composition of multiple captures involving 4 individuals or more in $M$. natalensis. Results of separate trap controls in parentheses, $\mathrm{m}$ - males, $\mathrm{f}$ - females, $\mathrm{A}-$ adult, $\mathrm{J}$ - juvenile.

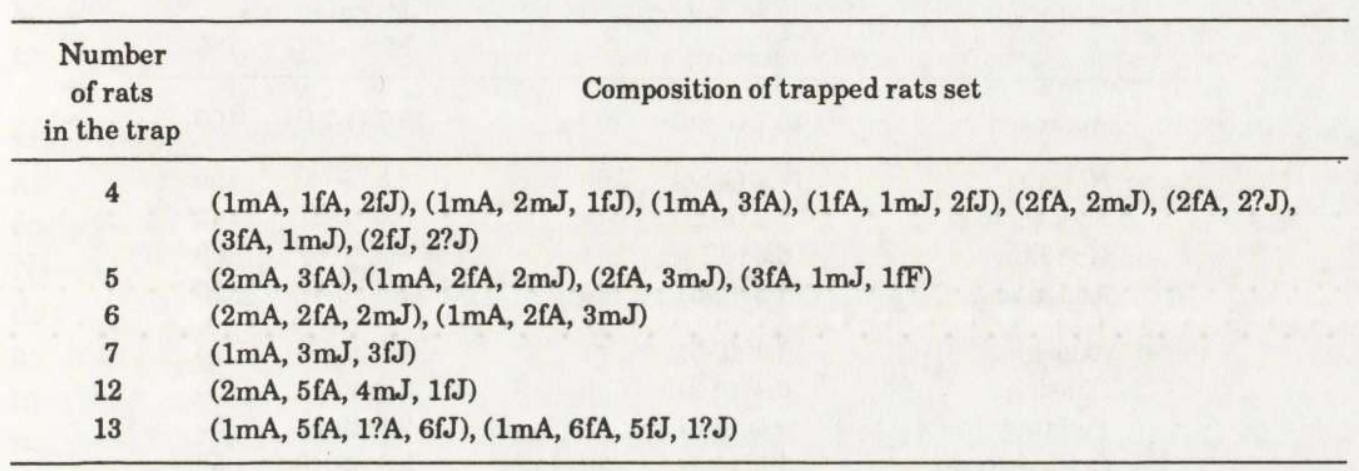

Fig. 1. Percentages of agonistic and neutral behaviours in dyadic encounters among males of $M$. natalensis and among males of M. huberti.

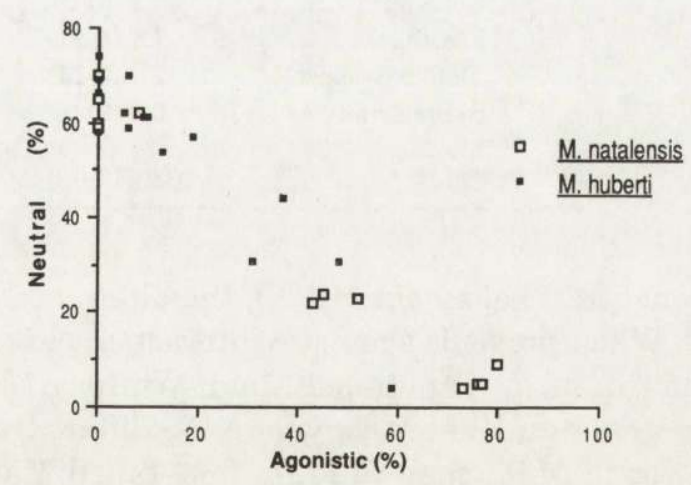

were mainly characterized by the relatively small number of adult males involved: 18 adult males versus 42 adult females (and 52 juveniles of both sexes). In only three captures were two adult males found together, whereas 2 to 6 females were captured together 13 times (Table 5). 


\section{Dyadic encounters}

The total numbers of behavioural acts are similar in M. natalensis (M. n.) and $M$. huberti $(M . h$.) (Table 6). The mean numbers of approaches and neutral behaviours are much lower in $M . n$. than in $M . h$. On the other hand, aggressive and defensive behaviours occur more frequently in encounters among $M$. $n$. males. All the agonistic (i.e. aggressive plus defensive) behaviours were grouped and their frequency $\left(\mathrm{P}_{\mathrm{ag}}\right)$ calculated as the percentage of the total number of behavioural acts in each encounter. When $\mathrm{P}_{\mathrm{ag}}$ is plotted against the percentage of investigative

Table 6. Mean numbers per encounter (M) and range of values (in brackets) for the different behavioural patterns recorded, and percentages of encounters displaying these patterns (P\%) in dyadic encounters among males of $M$. huberti ( $n=16$ encounters) and among males of $M$. natalensis $(n=12)$. a - neutral, b aggressive, and $\mathrm{c}-$ defensive behaviours.

\begin{tabular}{llrrrr}
\hline & \multicolumn{2}{c}{ M. huberti } & \multicolumn{2}{c}{ M. natalensis } \\
& \multicolumn{1}{c}{ M } & P\% & M & P\% \\
\hline \multirow{4}{*}{ a } & $13.7(7-26)$ & 100 & $10.7(4-21)$ & 100 \\
& Nosproach & $13.2(1-28)$ & 100 & $5.8(2-13)$ & 100 \\
& Following & $2.2(0-11)$ & 75 & $0.6(0-2)$ & 42 \\
& Huddling & $6.6(0-13)$ & 94 & $1.3(0-6)$ & 58 \\
& Allo-grooming & $1.5(0-5)$ & 69 & $0.5(0-4)$ & 25 \\
b & $1.1(0-5)$ & 44 & $4.1(0-14)$ & 58 \\
& Attacking & $0.1(0-2)$ & 6 & $2.2(0-8)$ & 33 \\
& Chasing & $0.5(0-3)$ & 31 & $2.6(0-9)$ & 50 \\
& Fighting & $1.0(0-5)$ & 50 & $3.4(0-16)$ & 58 \\
Offensive post. & $1.9(0-6)$ & 69 & $3.7(0-14)$ & 67 \\
c Retreating & $1.7(0-21)$ & 19 & $3.8(0-14)$ & 42 \\
& Fleeing & $2.7(0-11)$ & 62 & $4.7(0-15)$ & 58 \\
Defensive post. & $0.0(0-0)$ & 0 & $0.3(0-2)$ & 17 \\
Submission & & & & \\
& Total & $46.2(19-88)$ & - & $43.7(12-100)$ & - \\
\hline
\end{tabular}

(= neutral) behaviours $\left(P_{\text {inv }}\right)$, the difference between the two species appears (Fig. 1). When present, agonistic interactions are significantly more important in $M . n$. than in $M$. $h$. (one-tailed Mann-Whitney $U$ test, $p<0.01$, between 8 encounters in $M . n$. and 12 in $M$. $h$. where $\mathrm{P}_{\mathrm{ag}}$ differs from 0 ). Conversely, $\mathrm{P}_{\text {inv }}$ is significantly lower in $M . n$. than in $M$. $h$. (one-tailed Mann-Whitney $U$ test, $p<0.05$ ).

\section{Discussion}

Few studies describe the behaviour of $M$. natalensis. Veenstra (1958) described the species as very tolerant towards conspecifics, but the individuals studied were 
kept for generations in captivity. On the contrary, Coetzee (1975) reported experiments where wild-caught males fought to death when introduced in cages, "notwithstanding the fact that submissive behaviour was shown". The dyadic encounters described here (Table 6) obviously display the same kind of interaction: agonistic behaviours, when present, reach a high proportion of the total number of social interactions (Fig. 1). Although the percentage of tests showing such agonistic behaviours did not differ between the two species (67\% vs $68 \%$ ), intermale relationships in $M$. natalensis appear to be more aggressive on average than in $M$. huberti and also than in M. erythroleucus (Granjon 1987). These results could reflect effective differences in male interactions in the field, where males of $M$. natalensis seem to display mutual avoidance as shown by their tendencies to be involved in single rather than in multiple captures (Table 2), and to be rarely trapped with each others (Table 5). The intermale aggressiveness observed during dyadic encounters in $M$. natalensis may reflect a lack of interindividual and/or social rank recognition, as one would expect more mutual investigation and eventually submission (Vestal and Hellack 1978).

The grouping pattern observed in multiple captures of numerous individuals suggests that social units are generally composed of one adult male, a number of adult females and juveniles. The results presented here do not allow any conclusion about the familial nature of these associations, nor about their stability. Nevertheless, this grouping suggests a harem-like structure similar to the one described by Mihok (1979) for Peromyscus maniculatus, which can be classified as a polygynous mating system (see Dobson 1982 or Shields 1987). In such a mating system, males rather than females are likely to compete intensely for mates, as variance in reproductive output is greater in males than in females (Dobson 1982, Shields 1987). This would explain the observed intermale aggressiveness in dyadic encounters and avoidance in multiple captures. A similar interpretation corresponds to the "female (or harem) defense polygyny" (Emlen and Oring 1977), with males aggressively defending gregarious females against other males. This form of direct sexual selection is likely to favour an increase in male size, and thus an increase in sexual dimorphism. Polygamy appears to be associated with marked sexual dimorphism in rodents (Dewsbury et al. 1980). M. natalensis seems to fit this general rule, as it displays earlier (and more pronounced at adult age) sexual dimorphism in captivity for the major body measurements than the two other congeneric species from Sénégal, $M$. huberti and $M$. erythroleucus (Duplantier 1988).

The shift in sex-ratio observed between juveniles and adults (Table 1) may indicate that subadult males were excluded from the social group. Whether the lack of subalult males recorded during trapping sessions represents mortality or dispersal (in which case one must hypothesize that their probability of capture is lowered), it is probably related to the observed intermale aggressivity. This secondary skewed sex-ratio has no direct influence on equilibrium sex-ratio at birth (see Leigh 1 $\ni^{\prime} 70$ ), which was 1:1 in captivity (Duplantier 1988), but it has 
consequences on effective size of the populations. For instance, decreases in effective size of more than $10 \%$ for a $1: 2$ sex-ratio, and of $25 \%$ for a $1: 3$ sex-ratio are expected (Patton and Feder 1981, Futuyma 1986). These last values are likely to occur in social groups of $M$. natalensis as they can be described according to the results of multiple captures.

The relatively low genetic variability of $M$. natalensis as compared with the two other species of the genus in Sénégal (Duplantier et al. 1990b) may partly result from the social organization associated with the synanthropic way of life. Genetic drift phenomena associated with the consequences of group structure here presented (mainly the reduction of effective population size due to greater variance in reproductive success in males than in females and skewed sex-ratio) may help to explain this reduction in genetic variability in $M$. natalensis. In this hypothesis, gene flow associated with the transportation of some individuals by humans probably occur to prevent, or slow, inter-population differentiation.

Aknowledgements: We are grateful to Dr J. Cassaing and C. Baudoin for their comments on earlier drafts of this manuscript. We also thank $\mathrm{K}$. Ba for field assistance, J.F. Voisin for checking the English, and three anonymous reviewers for providing helpfull comments.

\section{References}

Bush G. L., Case S. M., Wilson A. C. and Patton J. L. 1977. Rapid speciation and chromosomal evolution in mammals. Proc. Nat. Acad. Sci. USA 74: $3942-3946$.

Chepko-Sade B. D. and Shields W. M. 1987. The effects of dispersal and social structure on effective population size. [In: Mammalian dispersal patterns. The effects of social structure on population genetics. B. D. Chepko-Sade and Z. T. Halpin, eds]. Chicago Press, Chicago: $287-321$.

Cockburn A., Scott M. P. and Dickman C. R. 1985. Sex ratio and intrasexual kin competition in mammals. Oecologia 66: $427-429$.

Coetzee C. G. 1975. The biology, behaviour, and ecology of Mastomys natalensis in Southern Africa. Bull. World Health Organization 52: 637 - 644 .

Crook J. H., Ellis J. E. and Goss-Custard J. D. 1976. Mammalian social systems: structure and function. Anim. Behav. 24: $261-274$.

De Graaf G. 1981. The rodents of Southern Africa. Butterworth and Co Ltd. Durban, Pretoria: 1-267.

Dewsbury D. A., Baumgardner D. J., Evans R. L. and Webster D. G. 1980. Sexual dimorphism for body mass in 13 taxa of muroid rodents under laboratory conditions. J. Mammal. 61: 146 - 149.

Dobson F. S. 1982. Competition for mates and predominant juvenile male dispersal in mammals. Anim. Behav. 30: 1183 - 1192 .

Duplantier J. M. 1988. Biologie évolutive de population du genre Mastomys au Sénégal. Unpublished Ph.D. Thesis, University of Montpellier, France: $1-215$.

Duplantier J. M. and Granjon L. 1988. Occupation et utilisation de l'espace par des populations du genre Mastomys au Sénégal: étude trois niveaux de perception. Sci. Tech. Anim. Lab. 13: 129 133.

Duplantier J. M. and Granjon L. 1990. Rythmes d'activité chez six espèces de Muridés du Sénégal appartenant aux genres Mastomys, Arvicanthis, Myomys et Dasymys. Mammalia 54: 173 - 182.

Duplantier J. M., Britton-Davidian J. and Granjon L. 1990a. Chromosomal characterization of three species of the genus Mastomys in Sénégal. Z. zool. Syst. Evolut.-forsch. 28: 289 - 298.

Duplantier J. M., Granjon L., Matthieu E. and Bonhomme F. 1990b. Structures génétiques comparées de trois espèces de rongeurs africains du genre Mastomys au Sénégal. Genetica 81: 179 - 192. 
Eisenberg J. F. 1967. A comparative study in rodent ethology with emphasis on evolution of social behaviour. Proc. U.S. Nat. Mus. Smithsonian Inst. 122: $1-52$.

Emlen S. T. and Oring L. W. 1977. Ecology, sexual selection, and the evolution of mating systems. Science 197: 215 - 223.

Futuyma D. J. 1986. Evolutionary biology. Sinauer Associates, Inc., Sunderland: 1-600.

Granjon L. 1987. Evolution allopatrique chez les muridés: mécanismes éco-éthologiques liés au syndrome d'insularité chez Mastomys et Rattus. Unpublished Ph.D. Thesis, University of Montpellier, France: 1 - 163.

Granjon L. and Duplantier J. M. 1991. Associations interindividuelles révélées par captures multiples chez plusieurs espèces de muridés au Sénégal (g. Mastomys, Arvicanthis et Rattus). [In: Le Rongeur et l'espace. M. le Berre and L. le Guelte, eds]. R. Chabaud, Paris: 231 - 242.

Grant E. C. and Mackintosh J. H. 1963. A comparison of the social postures of some common laboratory rodents. Behaviour 21: $246-259$.

Hubert B., Meylan A., Petter F. Poulet A. and Tranier M. 1983. Different species in genus Mastomys from Western, Central and Southern Africa (Rodentia, Muridae). Ann. Mus. Royal Afr. Centr., Sc. Zool. 237: 143 - 148 .

Kingdon J. 1974. East African mammals. Vol. IIB: Hares and rodents. London Acad. Press, London: $342-707$.

Lande R. 1979. Effective deme size during long-term evolution estimated from rates of chromosomal rearrangement. Evolution 33: 234 - 251.

Leigh E. G. 1970. Sex ratio and differential mortality between the sexes. Am. Nat. 104: 205 - 210.

Mihok S. 1979. Behavioral structure and demography of subarctic Clethrionomys gapperi and Peromyscus maniculatus. Can. J. Zool. 57: 1520-1535.

Robbins C. B. and Van Der Straeten E. 1989. Comments on the systematics of Mastomys Thomas 1915 with the description of a new West African species. Senckenberg. Biol. 69: 1 - 14 .

Rosevear D. R. 1969. The rodents of West Africa. British Museum of Natural History, London: 1 - 604.

Shields W. M. 1987. Dispersal and mating systems: investigating their causal connections. [In: Mammalian dispersal patterns. The effects of social structure on population genetics. B. D. Chepko-Sade and Z. T. Halpin, eds]. Chicago Press, Chicago: $3-24$.

Siegel S. 1956. Nonparametric statistics for the behavioral sciences. McGraw-Hill, Maidenhead: $1-312$.

Slade N. A. 1976. Analysis of social structure from multiple capture data. J. Mammal. 57: 790 - 795.

Veenstra A. J. F. 1958. The behaviour of the multimammate mouse, Rattus (Mastomys) natalensis (A. Smith). Anim. Behav. 6: 195 - 206.

Vestal B. M. and Hellack J. J. 1978. Comparison of neighbor recognition in two species of deer mice (Peromyscus). J. Mammal. 59: 339 - 346.

Wade M. J. and Breden F. J. 1987. Kin selection in complex groups: mating structure, migration structure, and the evolution of social behaviors. [In: Mammalian dispersal patterns - The effects of social structure on population genetics. B. D. Chepko-Sade and Z. T. Halpin, eds]. Chicago Press, Chicago: $273-283$.

Wilson A. C., Bush G. L., Case S. M. and King M. C. 1975. Social structuring of mammalian populations and rate of chromosomal evolution. Proc. Nat. Acad. Sci. USA 72: $5061-5065$.

Wilson D. S. and Colwell R. K. 1981. Evolution of sex ratio in structured demes. Evolution 35: $882-897$.

Zwicker K. 1989. Home range and spatial organization of the beach vole, Microtus breweri. Behav. Ecol. Sociobiol. 25: $161-170$.

Received 8 October 1992, accepted 13 February 1993. 